\title{
MARCADORES DISCURSIVOS E MULTIFUNCIONALIDADE: ATUAÇÕES TEXTUAIS DE ITENS VOLTADOS PARA A INTERAÇÃO
}

\author{
DISCOURSE MARKERS AND MULTIFUNCTIONALITY: \\ TEXTUAL FUNCTIONS OF INTERACTIVE ITEMS
}

\author{
Carla Regina Martins Valle | Lattes | carlavalle10@gmail.com \\ Universidade Federal de Santa Catarina
}

\begin{abstract}
Resumo: O objetivo do presente artigo é explorar as atuações de um grupo específico de marcadores discursivos interacionais, o grupo dos requisitos de apoio discursivo (RADs). Com base em uma perspectiva funcionalista de vertente norte-americana, descrevemos a multifuncionalidade de alguns desses RADs, itens basicamente interacionais, dando ênfase às suas atuações no plano textual, o que tem sido pouco explorado em trabalhos acadêmicos. Para isso, recuperamos os dados de Valle (2014), que examinou amostra de fala composta por 30 entrevistas com falantes da comunidade da Barra da Lagoa Florianópolis/SC (Amostra Brescancini-Valle), encontrando um total de 1.610 ocorrências. Como resultado, observou-se que os RADs, para além de atuarem no plano interacional, no plano cognitivo, no plano das atitudes do falante e no plano social/identitário, cumprem também funções no plano textual. Tais itens, para além de sua função básica interacional, têm o papel de colocar foco e determinadas porções textuais, contribuindo sobremaneira para a organização do fluxo da fala.
\end{abstract}

Palavras-chave: Marcadores discursivos; Multifuncionalidade; Funcionalismo; Gramática baseada no uso.

Abstract: This paper aims to explore the functions of a specific group of interactive discourse markers, based on a North American functionalist perspective. For this purpose, we describe the multifunctionality of these discourse markers, focusing on their textual functions, which have been less explored in academic works. We took the data (1.610 occurrences) from Valle (2014), who examined a speech sample composed of 30 interviews with speakers from the Barra da Lagoa community - Florianópolis / SC (Brescancini-Valle Sample). It was observed that those discourse markers, besides acting on the interactive level, on the cognitive level, on the speaker's attitudes level and on the social/identity level, also have functions on the textual level. These items, in addition to their basic interactive function, have the role of placing focus in some textual sections, contributing to the speech flow organization.

Keywords: Discourse markers; Multifunctionality; Functionalism; Usage-based grammar. 


\section{Introdução}

A natureza essencialmente dialógica da fala, que prevê a parceria com o interlocutor, faz com que pressões de ordem pragmática tenham força e até mesmo se sobreponham às normas previstas na sintaxe. Outros modos para organizar tópicos, frisar informações, conectar partes do texto oral são requisitados e, dentre os diversos elementos que auxiliam nessa tarefa, estão os marcadores discursivos (doravante MDs). ${ }^{1}$ Um dos subgrupos dos MDs reúne itens com atuações interacionais, os quais têm sido denominados de requisitos de apoio discursivo (doravante RADs) (MACEDO; SILVA, 1996), tais como sabe(s)?, entende(s)?, entendeu?, (en)tendesse?, tá(s) entendendo?, de interesse no presente artigo.

Schiffrin (2001) sugere que, embora tenham funções primárias derivadas de seus valores semânticos originais, os MDs são essencialmente multifuncionais e atuam em diferentes planos do discurso, ajudando a integrar os muitos processos simultâneos envolvidos na construção discursiva e colaborando para estabelecer a coerência. A autora salienta que:

[...] embora marcadores tenham funções principais [...], seu uso é multifuncional. É esta multifuncionalidade em planos diferentes do discurso que ajuda a integrar os vários processos simultâneos subjacentes à construção do discurso e assim ajuda a criar a coerência ${ }^{2}$ (SCHIFFRIN, 2001, p. 58, tradução nossa).

Schiffrin (1987) já caracterizava os MDs como dêiticos com funções indexicais, ou seja, o que os MDs fazem é apontar (ou refletir) as características do contexto discursivo em seus diversos planos: no plano da estrutura ideacional (relacionando ideias e proposições); no plano da estrutura de ação (a maneira pela qual os atos de fala se relacionam com porções discursivas); no plano da estrutura de troca (envolvendo os mecanismos de troca de turno); no plano do estado de informação (a gestão e organização do conhecimento e do metaconhecimento); e no plano da participação (envolvendo as relações en-

\footnotetext{
${ }^{1}$ Macedo e Silva (1996, p.11) propõem uma divisão funcional dos MDs em nove subgrupos: 1) Iniciadores - iniciam turnos (ah,bom, bem, olha $) ; 2$ ) requisitos de apoio discursivo - uso interativo para testar a atenção do interlocutor (né? tá? sabe? entendeu? viu? não é mesmo?); 3 ) redutores - modalizam a postura do locutor (eu acho, pô, sei lá); 4) esclarecedores - retomam com maior clareza partes do discurso (quer dizer, deixa eu ver); 5) preenchedores de pausa - preenchem o silêncio, enquanto o falante processa o que será dito (assim, hãa, bem); 6) sequenciadores - marcam sequência no discurso (aí, então, depois); 7) resumidores encerram uma lista de itens e resumem (e essas coisas, e tal, coisa e tal, e tudo); 8) argumentadores - iniciam argumentação contrária ao discurso precedente (agora, é mas, não mas, sim mas); e 9) finalizadores - dão fecho ao turno do falante (então tá, é isso aí, tudo bem).

2 “ $[\ldots]$ although markers have primary functions $[\ldots]$, their use is multifunctional. It is this multifunctionality on different planes of discourse that helps to integrate the many different simultaneous processes underlying the construction of discourse, and thus helps to create coherence."
} 
tre falante e ouvinte). Em suas considerações mais recentes, Schiffrin (2001) assume que os MDs podem funcionar simultaneamente em três domínios ou planos distintos - no cognitivo, no textual e no social/expressivo -, em que são requeridas diferentes habilidades comunicativas, como detalhado abaixo:

Domínio cognitivo: habilidade para representar conceitos e ideias através da língua.

Domínio textual: habilidade para organizar formas e transmitir significados dentro de unidades linguísticas maiores do que uma sentença. Domínio social e expressivo: capacidade de usar a linguagem para exibir as identidades pessoais e sociais, para transmitir atitudes e executar ações e negociar relações entre si e os outros (adaptado de SCHIFFRIN, 2001, p. 54).

Conforme salienta Valle (2014), a atuação em um dos planos não exclui os demais, e cabe destacar que o plano interpessoal/interacional é a própria essência dos RADs. Contudo, em alguns casos, um dos planos pode ganhar mais evidência. Sendo assim, o objetivo deste artigo é explorar as atuações dos RADs no plano textual, em que atuam colocando foco em certas porções textuais e auxiliam na organização do discurso oral. Cabe salientar que esta é apenas uma das facetas de atuação desses itens que decidimos explorar neste artigo, por não contarmos com muita literatura na área que tenha abordado os RADs deste ponto de vista ${ }^{3}$.

Com tal objetivo, recuperamos os dados de Valle (2014), dando destaque para o papel dos RADs como focalizadores discursivos. Foi examinada amostra de fala composta por 30 entrevistas com falantes nativos da comunidade da Barra da Lagoa Florianópolis/SC (Amostra Brescancini-Valle), encontrando-se um total de 1.610 ocorrências. Na seção seguinte, são apresentadas as bases teóricas do presente trabalho, além da problematização das funções dos RADs em diferentes planos. Logo após, o olhar recai sobre o plano textual e são caracterizadas as diversas atuações dos RADs como focalizadores. Em seguida, na seção 4, temos breve discussão e considerações finais. Por fim, na seção 5, constam nossas referências.

\section{Marcadores discursivos: a multifuncionalidade em questão}

$\mathrm{O}$ presente trabalho filia-se à abordagem funcionalista de vertente norte-americana - representada principalmente por pesquisadores da Costa Oeste Americana (Givón,

\footnotetext{
${ }^{3}$ Valle (2014) aborda a multifuncionalidade dos RADs ressaltando sua essência interacional e pragmática, mas o que fazemos aqui é apenas um recorte do trabalho que visa colocar luz nas atuações que envolvem a organização do discurso oral.
} 
Hopper, Bybee, Traugott, entre outros) e por seus interlocutores da Alemanha (Heine, Claudi, Hünnemeyer e Kuteva, entre outros). Segundo essa perspectiva, certas estratégias discursivas rotinizadas, devido ao uso que os falantes fazem delas em situação de comunicação, vão moldando e remoldando a gramática (BYBEE, 2010).

Para Givón, o que a gramática faz é convencionalizar certas estruturas que são mais frequentes e, portanto, mais adaptativamente relevantes, o que liberta parcialmente a comunicação humana da total dependência do contexto ${ }^{4}$. No entanto, constantemente, por pressões adaptativas, surgem novos contextos que são continuamente reinterpretados, o que faz com que o significado e a comunicação humana sejam permanentemente, em certa medida, dependentes do contexto, ganhando força a relação entre discurso e gramática. Givón, em seus escritos, não fornece uma definição clara de discurso, mas é possível depreender que ora se refere ao discurso multiproposicional, ou seja, ao texto; ora discurso remete a aspectos pragmáticos/relacionados à situação comunicativa (GIVÓN, $2002 ; 2011)$.

Os MDs são definidos por Traugott (1995) e Traugott e Dasher (2003), com base nos estudos de Schiffrin (1987) e Fraser (1996, 1999), como elementos cuja função principal é marcar as relações entre unidades do texto e que, embora essencialmente pragmáticos em função, têm papel sintático, fazendo parte da gramática da língua. Traugott (1995), que analisou os itens indeed, in fact e besides, de origem adverbial e atuações sequenciais, compartilha com Fraser a ideia de que os MDs são parte da gramática da língua. Nessa perspectiva, os MDs servem para que o falante dê sua avaliação não sobre o conteúdo do que é dito, mas sobre o modo como o que é dito é organizado. Em outras palavras, os MDs desempenham um papel metatextual.

Apesar de concordarmos com a atuação metatextual atribuída aos MDs, vemos problemas para o tratamento dos itens em análise nos moldes de Fraser, que presume uma estrita separação entre semântica (significado proposicional) e pragmática (significado pragmático) (FRASER, 1996; 1999). Uma crítica a essa visão disjuntiva, segundo Schiffrin (2001), é que ela minimiza várias funções importantes dos MDs, incluindo aquelas relacionadas à interação social.

Além disso, as visões de Schiffrin e de Fraser diferem bastante em relação a três questões importantes: a) com relação à fonte dos MDs - enquanto Fraser postula que a

\footnotetext{
${ }^{4}$ Contexto, nesse caso, pode ser entendido tanto como o contexto linguístico, em maior ou menor escopo, quanto como o contexto extralinguístico, situacional. Aliás, parece ser uma constante em Givón que o termo contexto receba maior ou menor dimensão a depender do caso. Em 2005, por exemplo, em Context as Other Minds, o foco está no contexto, que é entendido de modo bastante amplo como construto cognitivopragmático que integra o tripé vida (as relações sociais), mente (cognição) e linguagem (comunicação).
} 
contribuição do significado fonte e da classe gramatical de origem para o uso dos itens como MDs é mínima, as análises e considerações de Schiffrin sobre a multifuncionalidade dos itens sugerem que o significado fonte pode persistir e que as classes de origem muitas vezes são vistas como ponto de partida para uma expansão metafórica, de funções locais para funções globais (por exemplo, conjunções responsáveis pela junção de sintagmas ou orações, como and, podem passar a conectar porções textuais maiores e contribuir para a coerência discursiva); b) com relação aos MDs e o contexto discursivo - diferentes concepções de discurso produzem diferentes funções discursivas, por isso, enquanto Fraser limita o foco dos marcadores a relações entre proposições, Schiffrin inclui vários aspectos da situação comunicativa em seu modelo de discurso, tratando a indexação de relações proposicionais como apenas uma das inúmeras funções discursivas dos MDs; e c) com relação à integração da análise dos MDs no estudo da linguagem - enquanto a abordagem de Fraser relega a análise de muitos itens discursivos à pragmática, Schiffrin evidencia a interdependência entre semântica e pragmática, considerando os MDs como responsáveis pela coconstrução discursiva e simultaneamente atuantes em vários planos: cognitivo, expressivo, social e textual (SCHIFFRIN, 2001).

Essas diferenças entre as abordagens têm gerado controvérsias sobre o status de $y^{\prime} k n o w$, cognato de sabe?, que tem várias semelhanças funcionais com os itens que analisamos. Enquanto o item é incluído por Schiffrin no grupo dos MDs, ganhando lugar de destaque em sua obra clássica de 1987, Fraser (1996) o exclui do grupo dos MDs, afirmando que $y^{\prime} k$ now não sinaliza uma relação textual, mas apenas a atitude solidária do falante para com seu ouvinte.

O tratamento que Schiffrin (1987) dá a y'know revela um modo de entender discurso e significado compatível com nossas crenças e abordagens: i) entendendo que a linguagem reflete contextos discursivos ricos e multifacetados, o que impulsiona os pesquisadores a procurar nos dados todas as nuances (multi)funcionais dos MDs; e ii) supondo que o significado dos MDs é coconstruído pela interação falante-ouvinte, emergindo de relações sequenciais construídas em conjunto e de contingências próprias da conversação.

Mais especificamente sobre os RADs, Valle (2014) observa que, em alguns casos, apesar de sabe?, entende? (e demais formas correlatas) estarem em posição compatível ao seu papel como RADs, parecem estar em um ponto limítrofe entre verbo e marcador. Nesses casos, o plano cognitivo, em que interessam os conceitos ou ideias expressas através da língua, estaria em evidência - além, é claro, do plano interacional -, já que os itens são usados em contextos dialogais e com forte entonação de pergunta que costuma incitar a resposta do interlocutor, tal como vemos no trecho abaixo: 
(1) F: O meu pai, antes dele morrer:: ele mandou, quer dizer, eu já tava casada quando ele morreu, né?... aí ele mandou cada filho escolher um pedaço... são dez filhos... aieli chamou eu- eu- ((fala rindo)) o pior pedaço é o meu.

E: Por que que é o pior Fulana?

F: ((fala rindo)) Por que o meu terreno não é certo... ((ri bastante)) ele é de bico (est)... tendesse?

E: Entendi, [(inint)] (BARRA20FA8)

Há ainda atuações mais voltadas para o plano social/expressivo, mais precisamente para o plano das atitudes do falante. Essa atuação fica mais evidente quando associado ao uso dos RADs está o marcador discursivo assim. Em contextos comprometedores, assim $+R A D$, principalmente assim + sabe?, parece ter importante papel para a preservação da face, atenuando o enunciado, tal como no seguinte trecho:

(2) ... e:: nossa é super egoísmo assim sabe? da parte, principalmente de quem tá nesse mundo, não sei se- eu acho que já ficou bem claro assim, né? é hom- homossexualismo assim sabe? eu comecei nisso (est)... mas é um:: um mundo assim que eu vou te falar:: puff, é:: é aquela coisa muito vazia... muito vazia mesmo, de balada, de- de por exemplo assim ó, eu saí de eu relacionamento agora de um ano e meio... sabe?... com um outro menino... e:: quebrei a cara totalmente assim sabe?... (BARRA16MJ11)

No plano social/identitário, alguns RADs, tal como entendesse?, podem atuar como marcas de identidade de uma cultura local. Não é possível avaliar em que medida o falante faz uso consciente do RAD nesse plano, mas, no trecho abaixo, é sintomático o fato de que entendesse?, usado essa única vez pela entrevistada que prefere sabe?, apareça pela primeira vez aos 46 minutos de entrevista quando entra em jogo uma das temáticas mais polêmicas relacionada à identidade local e à vinda de novos moradores para o pequeno bairro da Barra da Lagoa, em Florianópolis/SC:

(3) Mas assim esse povo que vem, que vem e que finca a:: a sua raiz aqui... eu acho que é um povo::... mais difícil de se trabalhar porque ele acaba descaracterizando o teu ambiente (est)... sabe? é u (hes)...tipo a Barra como tem gaúcho, é tonelada de- nunca vi tanto (est)... e tu percebe isso quando tu pega ônibus Carla... sendo da/ daqui... tu percebe.. é só tu... ou tu ou mais um... tendesse? é difícil tu encontrar daqui... os demais são pessoas de fora que vem, que vão parando nessas paradas, que vão entrando nessas ruas (est)... povo que mora aí (BARRA09FJS-45:58; 46:13) 
Acrescente-se a isso o fato de que, sendo a entrevistadora da comunidade e amiga da entrevistada, parece ser instaurado um momento de cumplicidade entre as duas. A entrevistada chama a entrevistadora pelo nome, declara o pertencimento dela à comunidade nativa e evidencia o contraste entre nativos e moradores "de fora".

Para além de todas as atuações já mencionadas, há consenso entre vários pesquisadores sobre a característica principal e básica dos RADs como itens interacionais com atuação pragmática de contato com o interlocutor e muitos deles concordam que se trata de elementos multifuncionais que atuam principalmente em dois planos: no plano textual e no plano interacional (VALLE, 2001; GALUÉ, 2002; MÜLLER, 2005; ANDERSEN, 2007, entre outros).

\section{Os requisitos de apoio discursivo como elementos focalizadores}

Saber e entender, ao perderem características de verbos e atuarem como MDs, assumem progressivamente a macrofunção de viabilizar o processamento da fala e a recepção do ouvinte, que se manifesta a partir de um conjunto de funções ligadas à organização discursiva (MARTELOTTA; LEITÃO, 1998). Nesse sentido, o que os RADs fazem na prática é colocar foco e, ao frisar determinadas partes do texto, podem tanto cumprir objetivos pragmáticos relacionados ao interlocutor, quanto objetivos relacionados à organização textual/discursiva (VALLE, 2001). Tomando os RADs como elementos focalizadores, Valle (2014) propõe um quadro funcional, buscando integrar os planos interacional e textual.

Toma-se a noção de "foco" associada à noção de "relevo", que pode ser entendida como o grau de saliência dado a certas porções textuais/discursivas, tanto para destacá-las em relação a outras partes do texto (relevo positivo), quanto para rebaixá-las (relevo negativo). A marcação de relevo integra um componente textual, pois é um recurso de organização tópica do texto, e também um componente interacional, já que o modo como é feita a marcação de relevo explicita o direcionamento que o produtor do texto deseja dar à interação (TRAVAGLIA, 2006).

Dentre os recursos usados para a marcação de relevo - recursos fônicos (entonação, altura de voz, silabação, velocidade de fala ou ritmo, entre outros), recursos léxicos, recursos morfológicos/categoriais (aspecto, tempo), recursos sintáticos, estratégias de construção textual (parênteses, repetição, tematização) -, Travaglia (2006) elenca também os MDs, dando destaque para os prefaciadores textuais interativos (como olha e veja), marcadores de natureza bastante próxima aos RADs, que atuariam chamando a atenção do interlocutor para elementos e ideias dentro do texto. 
No caso dos RADs, o relevo normalmente em jogo é o positivo, ou seja, esses itens são usados para destacar certas porções discursivas, atuando tanto no plano interacional/ interpessoal (checando a compreensão do ouvinte ou apenas mantendo o canal comunicativo), quanto no plano textual (organizando quadros discursivos, já que, ao focalizar partes textuais, também sinalizam as relações estabelecidas no contexto linguístico).

Adotando a proposta de Ehlich (1981), Travaglia toma a noção de deixis textual de modo alargado, considerando que:

[...] as expressões dêiticas permitem ao falante obter uma organização da atenção comum dos interlocutores com referência ao conteúdo da mensagem. Para consegui-lo o produtor do texto tem necessidade de focalizar a atenção do parceiro sobre objetos, entidades e dimensões de que se serve em sua atividade linguística. (EHLICH, 1981 apud TRAVAGLIA, 2006, p. 204, grifo nosso).

Para o autor, o uso de marcadores prefaciadores seria um caso de relevo por dêixis textual, em que o falante colocaria foco em certas partes do texto como se estivesse sinalizando ao seu interlocutor: Olha/Veja, preste atenção no que vou dizer agora. Nesse sentido, poderíamos dizer que o uso dos RADs também seria um caso de relevo por dêixis textual, mas, nesse caso, o falante chama a atenção do interlocutor para algo que já foi dito, e o ingrediente interessante é que, ao focalizar (normalmente) o já dito, contribui como sinalizador de relações que se estabelecem entre aquilo que o antecede (e que geralmente é focalizado por ele) e aquilo que se pospõe ao item.

Valle (2014) procurou descrever a atuação dos RADs como elementos focalizadores, tomando como base a classificação feita em Valle (2001), mas logo percebeu a necessidade de remodelar o quadro funcional desses itens. A leitura dos dados transcritos ${ }^{5}$ das entrevistas nos dá uma ideia geral do tipo de atuação, mas a audição das gravações apresenta outra dimensão do uso desses itens: elevações no tom de voz, aceleração no ritmo de fala, pausas, curvas entonacionais, rupturas, entre outras características da fala, forneceram pistas mais seguras sobre o funcionamento dos RADs.

Passamos, então, a descrever os vários tipos de focalização, procurando detalhar o controle feito com o auxílio de trechos pinçados das entrevistas. Cabe ressaltar que não estamos afirmando que apenas os RADs são responsáveis por dar relevo e organizar o discurso oral, mas, certamente, em conjunto com outros elementos, contribuem para tal feito.

\footnotetext{
${ }^{5}$ Esse foi o procedimento adotado em Valle (2001).
} 


\subsection{Foco em situação (no passado, no presente e no futuro) e em discurso direto reportado}

Os RADs podem dar relevo a uma situação no presente ou a toda uma sequência de informações no presente sem ruptura temporal, incidindo sobre orações ou sobre trechos mais longos em que há a descrição, explicação, relato ou exposição de fatos, estados ou ações. Trata-se de uma atuação bastante recorrente, tendo sido contabilizados 252 casos, conforme ilustramos abaixo:

(4) F: Eu tomo quatro qualidade de remédio todo dia, eu tomo doze comprimido por dia.

E: Meu Deus!...É, mas também é um problema controlado, né? porque, quer dizer, se tem um remédio pra-

F: Pra controlar é, é assim ó... eu não posso, assim ó se eu varrer a casa eu canso, se eu falar muito eu canso... (est) se eu pegar um peso eu canso (est)... entendesse?... então também tem gente nova aqui. (BARRA34FB0:Faixa3-00:24) ${ }^{6}$

(5) E: Por que que tá sumindo o peixe?

F: Não, o peixe não tá sumindo, sabes? é época, né? que (hes) agora foi uma época de tainha deu bastante tainha, então agora tá parando, agora vai terminar a tainha, já vem outra pescaria (est) vem a brota, vem a corvina. (BARRA34FB0:Faixa7-01:04)

Nesse caso, o RAD tanto pode ter uma atuação mais neutra - checando a compreensão, o conhecimento compartilhado com o interlocutor e/ ou o canal comunicativo para poder dar sequência a informações corriqueiras -, como pode dar ênfase a alguma situação que mereça destaque. Em (4), em atenção ao questionamento da entrevistadora, há apenas a descrição de uma sequência de limitações da entrevistada decorrentes de seu problema de saúde, que é finalizada por entendesse?. Já em (5), diante da suposição equivocada de que o peixe estaria sumindo, a falante faz uso de sabes?, dando ênfase a uma informação que nega esse suposto fato.

A porção textual focalizada também pode ser uma situação no presente ou uma sequência de informações no presente, mas que está inserida em uma sequência de informações ocorridas no passado (nove casos do total de ocorrências), como ilustra o trecho abaixo:

\footnotetext{
${ }^{6}$ Nos exemplos, marcamos em itálico os trechos focalizados pelos RADs.
} 
(6) (Falando sobre a quantidade de comprimidos na sua caixa de remédios)

F: Aí eu cheguei ali agora fui comprar uma caixinha de remédio a:: a dona da farmácia ali (est)... eu disse::... "Eu quero uma caixinha de remédio", diz ela “Cem?”... “Não senhora... Cem como? Sem nada dentro?”... (risos da entrevistadora) ela assim "Ah”, ela agora botou pra rir diz ela "Não, com remédio", digo “Bom, então tá... mas você disse sem::”... porque o meu remédio é de ce- de cem, né? (est) unidades- unidade... (est) sabe?... então eu disse "Aquela caixinha de remédio", diz ela "De cem", eu digo "Não, sem nada eu não quero, dona." (BARRA45MB4:Faixa2-07:34)

Nota-se que em (6), ao contar sobre um episódio em que fez uma piada com a atendente da farmácia, o entrevistado parece se sentir inseguro quanto à compreensão da entrevistadora sobre o jogo de palavras feito por ele $(\mathrm{sem} / \mathrm{cem})$ e interrompe a narrativa, introduzindo um comentário explicativo que é destacado por sabe?. A própria mudança na sequência temporal já estabelece relevo e o RAD parece atuar para destacar ainda mais o comentário de fundo introduzido.

Esse tipo de uso já foi identificado nos trabalhos de Martelotta e Leitão (1998) e Martelotta (2004) para sabe? e entendeu? e nos trabalhos de Östman (1981) e Erman $(1987)^{7}$ para you know. É interessante notar que, nesse tipo de ocorrência, porque é comumente usado como elemento que quebra a narrativa para introduzir a sequência focalizada pelo $R A D$.

Do mesmo modo que podem colocar foco em situações no presente, os RADs também podem focalizar uma situação ou sequências de situações no passado sem ruptura temporal, incidindo sobre orações ou sobre trechos mais longos de narrativas factuais ou habituais em que há uma sequência de ações, explicações ou descrições no passado. Foram encontradas 242 ocorrências com foco em situação passada, o que representa uma grande fatia das atuações dos RADs como elemento focalizadores.

É importante notar que seria importante diferenciar os casos em que ofoco incide sobre porções discursivas maiores ou menores (não somente para o caso de foco em situação passada, mas também para o caso de foco em situação presente), mas nem sempre é simples delimilar o escopo de atuação focal dos RADs, principalmente quando não há ruptura temporal. Muitas vezes, rupturas tópicas, pausas, elevações na voz e o contorno entonacional dão conta de indicar o trecho focalizado. Outras vezes, é possível dizer apenas que o foco está em situação passada, mas sem a possibilidade de identificar claramente os limites da porção que recebe relevo. Os trechos abaixo ilustram tal situação:

\footnotetext{
${ }^{7}$ Os trabalhos de Östman (1981) e Erman (1987) foram acessados através das leituras sobre o texto de Müller (2005).
} 
(7) Essa farinha entrava naquele paiol... [...] então ela era empaiolada que era pra comer o ano inteiro (est) que só ia fazer a farinha o outro ano que vem (est)... sabe comé? aí nós pegava a fazer em maio, a farinha... em maio, em maio nós pegava a fazer a farinha, fazia maio, junho, julho... até perto de agosto, mês de agosto e setembro já era- era o mês da plantação (est)...tá entendendo? então nós fazia na- então essa farinha toda e guardava, é o que eu tô te explicando pra ti. (BARRA44MB5-06:42; 06:52)

(8) E: O que que cê falou pra ele?

F: Ah, eu disse "Pô, Fulano, assim::" a gente sempre conversava assim, sabe? eu disse pra ele que eu não aprendia nada com ele, daí ele assim "Ah, porque tu é uma faladeira que não sei o quê, que todo mundo aprende” (BARRA07FJ11:Faixa1-27:04)

Em (7), como o falante, depois do uso de sabe comé?, passa a tratar da distribuição dos meses do ano em função da produção de farinha, acreditamos que tá entendendo? esteja incidindo sobre todo o trecho assinalado. Contudo, a presença de pausa depois de julho e de elevação de voz em todo o trecho seguinte nos fez questionar até onde o RAD estaria atuando. Essa dificuldade já não foi encontrada na análise do dado em (8), em que uma ruptura na sequência tópica, para a introdução de um comentário de fundo, deixa claro o limite de atuação de sabe?.

Também há o caso em que o foco se projeta sobre situação passada, mas inserida em sequência de situações no presente (sete casos do total de ocorrências), como ilustrado abaixo:

(9) eu não sei nem o nome da santa mas é:: tem o pai, tem a mãe e tem o filho, então é da família.

E: Ah, [sim.]

F: [Eu ganhei] como a santa da família... entendesse?... então:::: de vez em quando eu acendo uma veli::nha... pra e::la, pra Nossa Senhora Apareci::da, agrade::ço... tás entendendo?... então:: é assim (BARRA20FA8-34:27)

Em (9), sem saber como denominar uma santa da qual é devota, a entrevistada introduz um comentário no passado, focalizado por entendesse?, que a ajuda a definir o nome da imagem que tem em mãos. Esse tipo de uso em que o RAD marca ou introduz comentário de fundo ou digressões já foi descrito em trabalhos anteriores (ÖSTMAN, 1981; ERMAN, 1987; MARTELOTTA; LEITÃO, 1998; MARTELOTTA, 2004). 
Foram encontradas 31 ocorrências em que os RADs atuam colocando foco em porções textuais que remetem tanto a eventos projetados como factuais no futuro (como em 10) - em que se tem a perspectiva concreta de realização (ainda que isso possa não ocorrer) - quanto a projeções hipotéticas (como em 11) - em que geralmente se expõem sonhos e desejos em relação ao futuro:

(10) O inverno já é mais tédio, frio, aí ninguém quer sair:: Hoje à noite eu ainda vou sair, sabe? E: Cê vai aonde?

F: Eu vou num:: churrasco na casa de um amigo meu. (BARRA02FJ8-32:47; 32:54)

(11) (Sobre religião e política)

O inimigo te bota muita dúvida... né? hoje eu tenho a certeza, falando contigo aqui eu tenho a certeza que Jesus Cristo é comigo... né? que ele tem um propósito na minha vida... ((voz de choro ou bocejo)) e eu espero que nunca eu decepcionar, né?... ((a voz volta ao normal $))$ um dia eu posso ser até um vereador um político aí:: ...tendeu? e tá decepcionando... e eu espero que:: nunca aconteça isso.

E: Não é da sua vontade. (BARRA31MA11:Faixa2-09:59)

Cabe salientar que, nesses casos, o trecho focalizado costuma ser pequeno, recaindo o foco sobre uma ou duas orações. Além disso, notamos que grande parte das ocorrências com esse tipo de funcionamento se encontra em tópicos discursivos relacionados à profissão e a estudos, sendo os mais jovens que costumam usar os RADs dessa forma, impulsionados pelos gatilhos das entrevistadoras, que, para essa faixa etária, sempre fazem perguntas que sugerem projeções futuras.

Em 35 das ocorrências da amostra, os RADs foram usados com foco em discurso direto reportado do próprio falante ou de terceiros, atuação tratada como função de you know, por Erman (1987) e Müller (2005), e de tu sais, por Andersen (2007). Nesses casos, o uso do RAD tem a dupla tarefa de dar relevo e também diferenciar o fluxo discursivo do falante da fala reportada, cumprindo, portanto, importante papel na organização textual, como ilustrado a seguir:

(12) Aí eu tô na intendência eu me pergunto "Pô, eu preciso de um computador pra trabalhar, eu preciso das máquinas, pra saber se eu não tô quebrando normas, pra botar os cara a trabalhar", entendeu? não tem, podia ser reivindicado pra intendência, [entendeu?]

E: [Claro.] (BARRA31MA11:Faixa1-09:32) 
(13) F: É tanto que tem:: pessoas que não sabem surfar, vão surfar no cantinho dos molhe, passa um perrenguezinho mas:: consegue:: segurar a ondar porque:: (hes) é tranquilo, mas em compensação quando ele vem pra esses duzentos metros pra frente que já tem que ter uma certa noçãozinha ele já passa um perrenguezinho, ele já fica meio:: já fica nervoso:: "Ah, meu Deus o que é que eu faço agora", entendeu?... tu vê e é uma coisa de cem a duzentos metros de dife[ren::ça](BARRA29MA11-15:41)

Percebemos que, em (12), o falante reporta sua fala através de eu me pergunto e fazendo o fechamento com o auxílio de entendeu?. Já em (13), o discurso reportado, e finalizado com entendeu?, é atribuído a qualquer pessoa que já tenha passado pelas dificuldades descritas. Nessa ocorrência, ao ouvir a gravação, fica nítida a mudança entre o discurso do falante e a fala reportada - quase como se fosse instaurado um momento para encenação -, e normalmente é fácil identificar a passagem entre discursos, pois, ao reportar, principalmente a fala de outros, o falante muda muitas das características de seu modo de falar, buscando intencionalmente a diferenciação ${ }^{8}$.

\subsection{Foco em comentário avaliativo}

Além de dar relevo a situações no presente, no passado e no futuro, os RADs também costumam lançar foco em comentários avaliativos no presente e no passado, com ou sem ruptura temporal.

Colocando foco em comentário avaliativo no presente, os RADs atuam dando relevo a trechos não muito extensos em que há algum juízo de valor (sobre uma pessoa, um fato, um comportamento etc.) ou em que o falante expõe seus gostos, vontades, posturas - sem, no entanto, se caracterizar como trecho de opinião ${ }^{9}$. Esse tipo de foco é o segundo mais recorrente em nossa amostra, somando 310 ocorrências, e é comum em trechos em que são descritas situações cotidianas, como nos segmentos ilustrados abaixo:

(14) Tem alguns aqui na Barra ainda que:: que vamos supor, que são:: que resolveram abrir um negócio (est) Como? É:: ser dono de uma:: de uma frota de barcos... como eu já, eu conheço, tem até na minha família são- tem duas pessoas que:: são dono

\footnotetext{
${ }^{8}$ As funções descritas neste bloco foram tratadas separadamente por Valle (2014), mas, no decorrer da análise, percebeu-se que não havia diferenças significativas que justificassem a separação. Sendo assim, todos os casos em que os RADs atuavam semelhantemente a um dos trechos acima descritos foram classificados em um só bloco denominado foco na situação e em discurso direto reportado, somando 577 ocorrências do total de 1.610 dados.

9 Veremos adiante que o foco em opinião é reservado para os momentos em que o falante de fato se posiciona sobre um tema, muitas vezes polêmico.
} 
de- de assim de barcos, aí te- aí é mais fácil, entendeu? porque eles controlam tudo, eles:: eles que comandam, vamos dizer, né? (BARRA13MJ11-05:50; 06:11)

(15) F: Sempre fui muito amiga de menino.

E: E os professores, como é que eles são?

F: Ah, são muito bons.

E: É?

F: Pegam bastante no nosso pé:: pra gente fazer as coisas cer::tas, tão sempre passando coisas no::vas, sempre ajudando a gente, sempre tirando dú::vidas, sempre:: sempre ajudando a gente, sabe? Nossa! Muito bom, muito bom. (BARRA02FJ8-05:00)

Em (14), temos um caso bastante típico em que o falante, durante uma sequência em que descreve a situação econômica de pescadores artesanais, utiliza entendeu? para colocar foco sobre pequeno trecho cujo conteúdo avaliativo é bastante nítido por conta da presença da construção adjetiva mais fácil. Já em (15), nota-se que o trecho focalizado pode parecer uma descrição, mas serve para reafirmar o juízo de valor que a entrevistada já havia expressado ao ser questionada pela entrevistadora sobre como são seus professores: ah, são muito bons. Em muitas outras ocorrências, a avaliação não é dada explicitamente no trecho focalizado, mas pode ser depreendida através da adjetivação de algumas construções ou da ideia geral expressa.

Também há casos em que o foco incide sobre comentário avaliativo no presente, inserido em uma sequência no passado, geralmente interrompendo fluxos narrativos. As porções discursivas sobre as quais recai este tipo de foco costumam não ser muito grandes e são bem delimitadas não só pela presença do RAD, mas também pela ruptura temporal e muitas vezes também por mudança no ritmo de fala e na altura da voz. O uso de itens como mas, que e principalmente porque é comum no início dos trechos focalizados e contribui para a sua delimitação, como evidenciam os trechos abaixo:

(16) (Sobre o começo do namoro com a atual esposa)

Aí:: ela:: tava em:: procurando igreja... né? e eu sabia que ela não tinha esse espírito... mas a gente quando é da igreja a gente não:: a gente sabe o que é mais forte, entendeu?... aí:: eu namorei ela, eu também já não queria mais saber de namorada assim, né? (BARRA31MA11:Faixa2-11:03)

(17) ...eles pegaram, tavam fazendo um churrasco, aí eu tava com o meu vô sentado eles pegaram- pegaram uma sacola, os lixo, de carne esses negócio tudo e jogaram no rio, 
né? aí eu fui falar, né? porque não pode (hes)... se bem que peixe come, mas a sacola não, a sacola vai ficar boiando, vai:: vai poluir o rio, entendeu?... aí ele achou ruim ainda que eu tava falando... (BARRA12MJ9:Faixa1-13:23)

A focalização de comentários avaliativos com relevância presente, apesar de não ser muito recorrente, tendo sido identificada apenas 20 vezes na amostra, tem um componente especial que a diferencia da anteriormente descrita, pois a ruptura temporal, que introduz um comentário de fundo, dá ainda mais destaque à avaliação do falante que parece buscar a concordância do ouvinte. Como observamos em (16), em meio a uma narrativa sobre como o entrevistado e a esposa se conheceram e começaram a namorar, há a introdução de um comentário avaliativo com relevância presente, focalizado por entendeu?, com o propósito de evidenciar ao entrevistador a importância da religião na vida do casal. Aliás, a religião é o tema central de quase todas as situações relatadas na entrevista, como se o falante buscasse convencer o outro de sua fé, catequizá-lo. Também em (17), enquanto narra um episódio em que discutiu com um turista, outro falante introduz comentário avaliativo no presente que serve para expressar seu juízo de valor contrário à atitude do turista e também parece servir como estratégia para que o entrevistador concorde com sua avaliação.

Os RADs atuam em trecho de referência temporal passada, semelhantemente a quando colocam foco em comentário avaliativo no presente, dando relevo a trechos em que há algum juízo de valor (sobre uma pessoa, um fato, um comportamento etc.) ou em que o falante expõe seus gostos, vontades, posturas. Em nossa amostra, temos 187 ocorrências em que os RADs apresentam esse tipo de atuação, normalmente em meio a sequências narrativas, ou em descrições no passado, como ilustrado abaixo:

(18) É, a turma sempre foi unida, principalmente no (hes) primeiro, segundo, terceiro ano assim, sabe?... sempre, sempre, sempre a gente fazia esporte jun::tos era- era uma coisa bem legal assim, bem bacana. (BARRA16MJ11-02:12)

(19) F: Mas a escola ali na Barra tava horrivel assim, tu tinha até nojo de se encostar na parede assim de tão suja, sabe? os vidro assim ó, as merendeira não limpavam os vidro, né? fulano?

I: Não limpam.

F: Não limpam, é... os vidro assim tu não via nada do outro lado, sabe?... nada, a poeira assim era tanta que tu não via, tu vivia espirrando dentro da sala... (BARRA07FJ11:Faixa1-19:24; 19:34) 
Tanto em (18) como em (19), sabe? é usado em trecho de descrição no passado para focalizar uma avaliação também feita no passado. Destaca-se o segundo RAD em (19), em que a aparente descrição os vidro assim tu não via nada do outro lado trata-se de comentário avaliativo que poderia ser facilmente traduzido por os vidros eram muito sujos. É importante salientar que, em alguns casos, os falantes produzem longos trechos avaliativos no passado, mas normalmente foi possível identificar os limites de atuação dos RADs através de outras marcas de relevo como elevação do tom de voz e pausas.

Foram identificados apenas 10 casos em que os RADs atuam com foco em comentário avaliativo com relevância passada. Nesse tipo de ocorrência, o foco também incide sobre comentário avaliativo no passado, mas introduzido em meio à sequência de referência temporal presente. Normalmente ocorre quando o falante, enquanto argumenta, descreve ou expõe fatos no presente, faz pequenos comentários ilustrativos no passado (como em 20) ou avalia fatos anteriormente narrados que se vinculam à linha argumentativa que vinha sendo desenvolvida (como em 21):

(20) ... e na igreja tu acaba descobrindo um monte de coisa assim, né? por exemplo:: na verdade não era nem da minha vontade porque eu-eu sou meio- meio receio eu fiquei com meio receio assim, sabe?...porque eles falam que quando tu sobe no altar tu não quer cantar pro público que tá ali, tu canta pra Deus, entendeu?... (BARRA16MJ11-32:25)

(21) (Sobre o relacionamento tenso com a filha)

F: A gente dá medo (est) quando a pessoa passa uma fase, passa uma fase complicada, dá medo depois de fazer outra fase, (est) né? não [é fácil, é assim]

E: [É verdade...] fica meio traumatizado, né?

F: Não, fica, fica, fica, fica, não é fácil... então::... aî foi::... não adiantou de nada, nem pra eles, nem pra mim não adiantaram de nada... fazer essas coisas... (est) sabe? sou um homem que trabalhava ta::nto, tomei tanto conta da minha famí::lia... (BARRA45MB4:Faixa2-06:01)

Nesse caso, apesar de terem sido percebidas estas sutis diferenças entre os vários tipos de avaliação, todos os casos foram agrupados, somando 527 ocorrências do total de 1.610 dados.

\subsection{Foco na opinião do falante}

Os RADs costumam ser muito recorrentes lançando foco na opinião do falante, somando 313 ocorrências na amostra investigada. Nesses casos, o plano interacional 
está mais evidente, já que o falante parece engajado em convencer o interlocutor e pedir uma confirmação, não da compreensão, mas da validade de seus argumentos e opiniões. Geralmente há a presença de pistas contextuais que evidenciam que o falante se posiciona (como o uso de pra mim, eu acho que, na minha opinião), outras vezes, na falta de pistas evidentes, a temática e a tomada de posição é que deixam clara a natureza do trecho que recebe foco, o qual costuma ser longo e, muitas vezes, se confunde com a própria sequência argumentativa em que ocorre. Sendo assim, não é tarefa simples (e muitas vezes torna-se inviável) saber quais os limites de focalização do RAD, que em muitas ocorrências se apresenta com escopo amplo. Observemos os trechos abaixo:

(22) F: É porque cada um tem as suas- no caso eu penso de um jeito você pensa de outro, mas são todos seres humanos feitos de carne e osso...entendeu? então eu acho que... a educação em primeiro lugar que ser mal educado, ser grosseiro não adianta (est)... não leva ninguém pra lugar nenhum, entendeu? só vai chegar:: no mesmo lugar onde saiu. (BARRA04FJ9:Faixa2-13:05; 13:14)

(23) F: aí faz:: faz qualquer coisa aqui na Barra, é um que só vai contra outro e eu acho que deveria ter mais união...tendesse? que a Barra da Lagoa tá precisando de mais união e olhar mesmo as pessoas e também na época de eleição e votar nas pessoas certa, porque:: como tá sendo o governo e a- e a prefeita aí não:: (hes)... tendesse? tão sempre tudo:: tá,eu não acho que eles tão:: pra minha opinião não tá sendo boa coisa não, porque eles tem que olhar mais pros pobres, não pros ricos... simplesmente esse negócio do BESC agora ó...entendesse?

E: Que negócio?

F: Esse negócio do BESC aí que eles agora privatizaram o BESC aí (est) vai ter muito desemprego, então eles tinham que olhar pras pessoa que- que precisa de emprego, porque o desemprego tá grande... Aí dá o quê? Vai dar rou::bo...tendesse? aí as pessoa falam aí que vem esses desabrigado, de gen- vai dar roubo, vai dar muita morte... (BARRA27MA8:Faixa1-04:02; 04:23; 04:34)

Em (22), ao ser questionada sobre sua opinião em relação ao turismo, a entrevistada defende a posição de que turista bom é turista educado. Vemos que, nesse caso, o escopo dos dois RADs no trecho é bastante amplo: a única marca evidente para delimitar o escopo do segundo é a presença do primeiro. Em (23), há três ocorrências em que o RAD coloca foco sobre a opinião do falante: o primeiro sinaliza trecho em que o entrevistado defende a necessidade de mais união no bairro; o segundo dá relevo à opinião do falante sobre a atitude dos políticos locais; o terceiro coloca foco na tese de que privatizações levam a de- 
semprego. Cabe ressaltar que na, segunda ocorrência ilustrada, foi possível delimitar que o escopo do RAD corresponde a todo o trecho em destaque por conta de outras estratégias de relevo, já que, a partir do primeiro tá, o falante altera o tom de voz e acelera a fala.

\subsection{Foco prospectivo}

O uso dos RADs com foco prospectivo ocorre 94 vezes em nossa amostra. Essa é a atuação que mais se distingue das demais e já havia sido identificada em Valle (2001) apenas para sabe?. Nesse caso, há um deslocamento na direção do foco dos RADs, que, ao invés de incidir sobre o que está anteposto a eles, se projeta ao que está posposto, em uma espécie de movimento catafórico. Observa-se, geralmente, pausa anterior ao RAD, entonação de pergunta bastante atenuada ou inexistente e a formação de um conjunto entonacional entre $\mathrm{RAD}$ e o trecho declarativo focalizado, como ocorre abaixo:

(24) (Sobre a diversão na adolescência)

F: Fazia a festa as- a nossa adolescência foi isso assim (est)... sabe(?) aniversário aqui ali, uma festinha desse tipo... discoteca olha, eu acho que eu tinha... eu já tinha mais de quinze anos quando eu comecei a ir (BARRA09FJS-12:39; 12:51)

(25) (Sobre os poucos recursos de alguns turistas)

F: É, aí depois de terminar as férias vão embora trabalhar, eles manda ver, é isso aí que eles vivem, né? os argentino vive aí disso aí, né?... tendesse(?) os argentino querem isso aí, porque vi- eles procuram, cada ano eles vem mais esperto (BARRA27MA8:Faixa2-24:04)

Nas duas ocorrências, o plano textual parece estar em evidência e os RADs podem ser substituídos por expressões como pois é e ou seja. O plano interacional continua presente, já que é característica constitutiva dos RADs, mas perde força, o que é evidenciado pela junção entre $\mathrm{RAD}$ e trecho posposto que inviabiliza qualquer tipo de resposta do interlocutor.

\subsection{Foco Pragmático}

Observamos que os RADs também podem atuar com foco pragmático, um tipo de foco mais amplo, que abarca não uma porção textual específica, mas toda uma situação dialogal ${ }^{10}$. Esse caso, que ocorre 64 vezes em nossa amostra, já foi ilustrado no início des-

\footnotetext{
${ }^{10}$ Ressaltamos que os RADs são elementos que sempre mobilizam aspectos pragmáticos, já que, interacionais em essência, sempre envolvem o contato com o interlocutor e com a situação comunicativa, buscando o engajamento do parceiro no diálogo. No entanto, decidimos rotular este tipo de foco como "pragmático" porque, em alguns casos, a busca por tal engajamento é colocada em evidência.
} 
ta seção quando comentamos algumas ocorrências em que o plano cognitivo estava em evidência. De fato, nessa atuação, dois planos ganham força: o cognitivo - na medida em que o significado lexical de verbo ainda parece se manter; e o interacional - ao passo que é um uso comum em contextos dialogais e o RAD costuma apresentar forte entonação de pergunta. É um funcionamento que se dá no jogo dialogal falante-ouvinte, envolvendo trocas de turno e o engajamento ativo do interlocutor, sendo usado pelo falante para mobilizar atitude responsiva (por parte do interlocutor) ou para calar o interlocutor e fazer a retomada do turno, como ilustram os trechos abaixo:

(26) F: Até:: mil novecentos e setenta e-... é:: setenta e oito, setenta e nove foi uma época boa.

E: Uma época [que dava um bom dinheiro.]

F: [Foi... foi,] foi, foi, foi, foi, foi, todo mundo aqui cresceu.

$\mathrm{E}: \mathrm{Ah}$, foi geral assim.

F: É, foi geral (est)... veio um desenvolvimento, entendesse?

E: Sim.

F: E:: surgiu outros tipos de pesca que não tava na- como a lula, o bacalhau, a tal de brota. (BARRA42MB3:Faixa1-11:05)

(27) F: Agora quem vem de carro sempre tem uma coisinha e quem não tem que pega ônibus aí, vem de ônibus, ah:: trinta e seis horas da Argentina até aqui pra passar dez, quinze dia.

I (filha do informante): Pai, tá chovendo.

F: Eu sei.

I: Tem roupa na rua.

F: Então vai lá buscar.

I: Mas tem muita.

F: Ah:: não tá chovendo... (Dirigindo-se novamente à entrevistadora) tendesse? mas [é::]

E: [ (inint)]

F: Ah, é, eles é assim e eu acho que eles não tão errado não, tendesse? eles tem que ver, procurar também, né? (BARRA27MA8:Faixa2-25:38)

Os dois trechos ilustram os dois tipos de ocorrências que estamos tomando sob o rótulo de foco pragmático. No primeiro, o RAD remete a toda uma sequência de trocas de turno, muitas vezes introduzida por uma dúvida do entrevistador. Em (26), o entre- 
vistado vinha discorrendo sobre o desenvolvimento da pesca entre as décadas de 1960 e 1970 quando a entrevistadora toma o turno e, depois de algumas trocas, entendesse? é usado para remeter a toda a situação dialogal anterior e também a toda a temática sobre o desenvolvimento.

No segundo caso, depois de grande quebra no fluxo discursivo por conta de longas digressões, ou pela interrupção de um interveniente (ou do próprio entrevistador) para tratar de outros temas, o falante faz uso do RAD para reativar o foco naquilo que estava sendo dito antes da quebra. Em (27), o entrevistado falava sobre a situação econômica dos turistas argentinos que procuram a Barra da Lagoa nas férias, quando é interrompido por sua filha. Depois de sucessivas trocas de turno com a filha, ele se dirige à entrevistadora e usa tendesse?, retomando ao mesmo tempo a interlocução com ela e sua exposição sobre os turistas argentinos.

\subsection{Foco na busca de informação}

Os RADs parecem ser utilizados para marcar a busca por expressões ou pelo conteúdo a ser dito, atuação já levantada por Östman(1981), Erman (1987) e Müller (2005) para you know. É importante notar que se trata de uso bastante especial, já que, nesse caso, o foco não está em nenhuma porção textual específica e nem se dirige ao interlocutor. $O R A D$ parece se voltar para o processamento da informação pelo falante, que tenta ganhar tempo e ao mesmo tempo buscar em sua memória o que quer comunicar. Esses casos representam uma fatia pequena de nossas ocorrências, apenas 35 casos, que ilustramos através dos trechos a seguir:

(28) (Sobre os turistas estrangeiros: americanos e europeus)

F: Eles- é só pra isso e o argentino é distinto, o argentino já vem pra-... entendeu::? sol, noite, são distinta coisa, o americano ele nem gosta do sol ele, ele- quando tem sol ele trata de- de se recuar, ele aqui ele se recua muito (BARRA19FA8-05:08)

(29) (Sobre os trabalhos que já exerceu)

F: Tô trabalhando agora na linha, mas eu também já trabalhei de serven::te, mas eu também fiz vários- vários serviços [também]

$\mathrm{E}:[\mathrm{E}$ ?]

F: É:: eu fiz muito... tem que:: só:: tendesse? já trabalhei em vários serviços, também pesquei um pou::co, ialá fora com os cara sem::pre...(BARRA27MA8:Faixa2-27:26)

Em (28), o falante, imediatamente após a quebra do fluxo discursivo e pausa breve, usa entendeu? um pouco alongado como se buscasse a informação que logo em seguida é 
encontrada e esclarece o trecho truncado anterior ao RAD. Em (29), a quebra é maior, e o falante parece ter mais dificuldade para retomar o fluxo discursivo, fazendo uso de vários alongamentos vocálicos, pausas e tendesse? até a retomada.

\section{Considerações finais}

Em síntese, cabe notar que a maioria dos RADs cumpre atuações com foco na opinião do falante (313 ocorrências), foco em comentário avaliativo (527 ocorrências) e foco em situação e em DDR (577 ocorrências), com destaque para os dois últimos tipos de foco citados, que, juntos, concentram 1.104 dados, 69\% do total. Esses dois tipos de atuação parecem ser os mais prototípicos, em que os RADs, em equilíbrio, ainda podem manter certa força no plano interacional, mas já contribuem para a organização do discurso oral no plano textual.

Apresentamos, no Gráfico 1, a frequência geral dos RADs em cada tipo de foco identificado na análise:

Gráfico 1: Distribuição geral dos RADs em relação aos tipos de foco

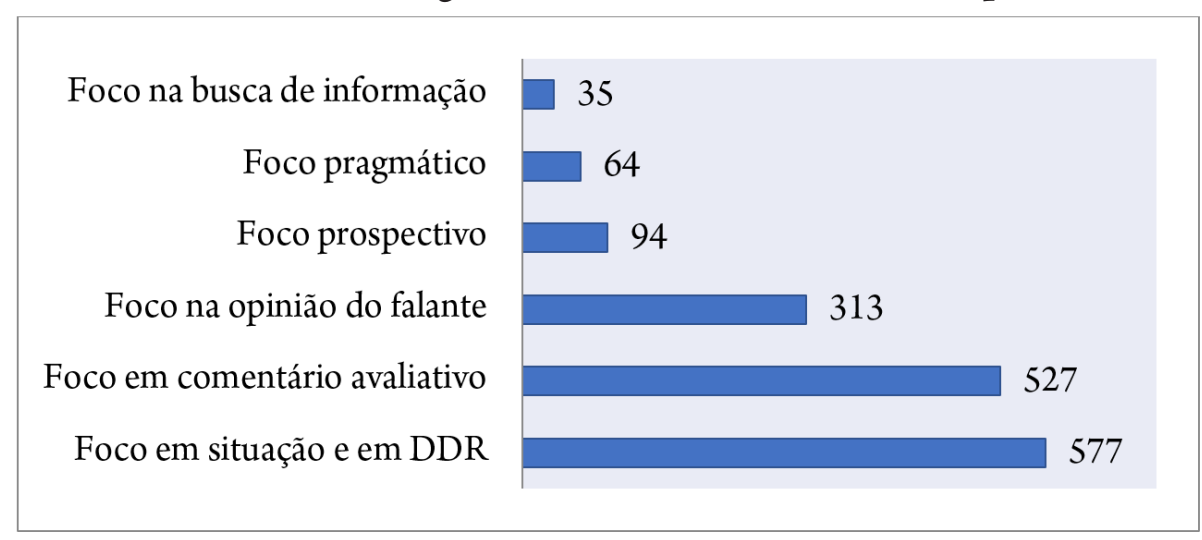

Fonte: Valle (2014).

Apenas a partir da década de 1980, com o reconhecimento de que itens discursivos carregam significado social, realizam funções na interação discursiva e fazem parte da gramática (considerando-se uma visão funcional mais alargada de gramática), é que o interesse acadêmico sobre itens dessa natureza ganhou fôlego (PICHLER, 2010). Apesar de frequentemente marginalizadas e consideradas como 'vícios de linguagem' (evidência de manifestações verbais desarticuladas e disfluentes), essas expressões, típicas da oralidade cotidiana, são extremamente recorrentes e têm importante papel, não apenas para garantir a manutenção da interação com o interlocutor, mas também para cumprir várias tarefas para a organização textual/discursiva. 


\section{Referências}

ANDERSEN, Hanne Leth. Marqueurs discursifs propositionnels. Langue française, $n$. 154, p. 13-28, 2007.

BYBEE, Joan. Language, Usage and Cognition. Cambridge: Cambridge University Press, 2010.

FRASER, Bruce. What are discourse markers? Journal of Pragmatics, v. 31, p. 931-952, 1999.

FRASER, Bruce. Pragmatic markers. Pragmatics, n.6(2), p. 167-190, 1996.

GALUÉ, Dexy. Marcadores conversacionales: un análisis pragmático. Boletín de Lingüística, Universidad Central de Venezuela, Caracas, v. 18, p. 27-48, 2002.

GIVÓN, Talmy. Compreendendo a gramática. Tradução e adaptação: Maria Angélica Furtado da Cunha; Mário Eduardo Martelotta; Filipe Albani. Natal: EDUFRN, 2011 [1979].

GIVÓN, Talmy. Bio-linguistics: the Santa Barbara lectures. Amsterdam/Philadelphia: John Benjamins Publishing Company, 2002.

MACEDO, Alzira; SILVA, Giselle Machline de Oliveira. Análise sociolinguística de alguns marcadores conversacionais. In: MACEDO, Alzira; RONCARATI, Cláudia; MOLLICA, Maria C. (Orgs.).Variação e discurso. Rio de Janeiro: Tempo Brasileiro, 1996. p. 11-49.

MARTELOTTA, M. E.; LEITÃO, M. Igualdades e diferenças nos marcadores discursivos sabe? e entendeu? In: Artigos produzidos pelo Grupo Discurso \& Gramática sobre gramaticalização no português do Brasil. UFRJ, Rio de Janeiro, 1998. Mimeo.

MARTELOTTA, Mário E. Operadores argumentativos e marcadores discursivos. In: VOTRE, Sebastião J.; CEZARIO, Maria Maura; MARTELOTTA, Mário E. (Orgs.). Gramaticalização. Rio de Janeiro: Faculdade de Letras UFRJ, 2004. p. 82-136.

MÜLLER, Simone. Discourse markers in native and non-native english discourse. Amsterdam /Philadelphia: John Benjamins Publishing Company, 2005.

PICHLER, Heike. Methods in discourse variation analysis: reflections on the way forward. Journal of Sociolinguistics, 14/5, p. 581-608, 2010.

SCHIFFRIN, Deborah. Discourse markers: language, meaning and context. In: SCHIFFRIN, Deborah; TANNEN, Deborah; HAMILTON, Heidi E. (Eds.). The handbook of discourse analysis. Malden, MA: Blackwell, 2001. p. 54-75.

SCHIFFRIN, Deborah. Discourse markers. Cambridge: Cambridge University Press, 1987. TRAUGOTT, Elizabeth Closs. The role of the development of discourse markers in a theory of grammaticalization. Manchester: Stanford University, 1995, p.1-29.

TRAUGOTT, Elizabeth Closs; DASHER, Richard B. Regularity in semantic change. 2. ed. Cambridge: Cambridge University Press, 2003. E-book. 
TRAUGOTT, Elizabeth Closs; KÖNIG, Ekkehard. The semantics-pragmatics of grammaticalization revisited. In: TRAUGOTT, Elizabeth Closs; HEINE, Bern (Eds.). Approaches to grammaticalization: focus on theoretical and methodological issues. Amsterdam / Philadelphia: John Benjamins Publishing Company, v. 1 e 2, 1991. p. 189218.

TRAVAGLIA, Luiz Carlos. O relevo no processamento da informação. In: JUBRAN, Clélia Cândida Abreu Spinardi; KOCH, Ingedore Grunfeld Villaça (Orgs.). Gramática do português culto falado no Brasil. Campinas: Editora da UNICAMP, 2006. p. 167215.

VALLE, Carla Regina Martins. Sabe? não tem? entende?: itens de origem verbal em variação como requisitos de apoio discursivo. 2001. Dissertação (Mestrado em Linguística) - Programa de Pós-graduação em Linguística, Universidade Federal de Santa Catarina, Florianópolis, 2001.

VALLE, Carla Regina Martins. Multifuncionalidade, mudança e variação de marcadores discursivos derivados de verbos cognitivos: forças semânticopragmáticas, estilísticas e identitárias em competição. 2014. Tese (Doutorado em Linguística) - Programa de Pós-graduação em Linguística, Universidade Federal de Santa Catarina, Florianópolis, 2014. 